\title{
The Effect of Scrotal Circumference on Pregnancy Rates in Mpwapwa Breed Cattle During September - November 2020 Breeding Season at Taliri Mpwapwa Farm in Tanzania Kabuni Thomas KabUni ${ }^{*}$, Richard LaVEN ${ }^{2}$
}

${ }^{1}$ Tanzania Livestock Research Institute (TALIRI), Department of Cattle Research, P.O.Box 202, Mpwapwa, Tanzania; ${ }^{2}$ Massey University, School of Veterinary Science, Private bag 11 222, Palmerstone North 4442, New Zealand.

\begin{abstract}
The goal of this study was to assess the effect of scrotal circumference (SC) on conception rates in Mpwapwa breed cattle during the Sept - Nov 2020 breeding season. Eight Mpwapwa bulls aged $\geq 3$ years were selected from 23 bulls which had passed a structural soundness and movement tests based on having the largest SC and used to mate 324 non-pregnant Mpwapwa cows. Mating was conducted in eight groups with each group randomly assigned a single bull. For each bull, data were collected on age, pre-breeding body condition score (BCS) and body weight, SC and total number of cows bred. Based on $\mathrm{p}<0.25$ value in a univariable model with pregnancy rate as the outcome variable, all of the variables except bodyweight were included in a multivariable logistic regression model with pregnancy rate as the outcome variable. Of those variables only pre-breeding BCS was clearly associated with odds of pregnancy. Compared to a bull with a BCS of 3.5 , a bull with a BCS of 3.0 had only 0.29 times the odds ( $95 \%$ confidence interval (CI) 0.15 to 0.57 ) of getting a cow pregnant during the breeding season. For SC, the data were compatible with a small decrease and a moderate increase in the odds of pregnancy (odds ratio for a $1 \mathrm{~cm}$ increase in $\mathrm{SC}$ was 1.05 (95\% $\mathrm{CI} 0.84$ to 1.3 )). Further research on the association between SC and pregnancy rate in Mpwapwa bulls is needed, including identifying whether there is an interaction between BCS and SC and their effect on subsequent fertility.
\end{abstract}

Keywords | Breeding soundness evaluation, Reproductive performance, Fertility, Mating and Mpwapwa breed cattle

Received | July 21, 2021; Accepted | August 08, 2021; Published | September 15, 2021

*Correspondence | Kabuni Thomas Kabuni, Tanzania Livestock Research Institute (TALIRI), Department of Cattle Research, P.O.Box 202, Mpwapwa,

Tanzania; Email: kabuni.kabuni@gmail.com

Citation | Kabuni KT, Laven R (2021). The effect of scrotal circumference on pregnancy rates in mpwapwa breed cattle during september - november 2020 breeding season at taliri mpwapwa farm in tanzania. J. Anim. Health Prod. 9(4): 357-361.

DOI | http://dx.doi.org/10.17582/journal.jahp/2021/9.4.357.361

ISSN | 2308-2801

Copyright (C) 2021 Kabuni and Laven. This is an open access article distributed under the Creative Commons Attribution License, which permits unrestricted use, distribution, and reproduction in any medium, provided the original work is properly cited.

\section{INTRODUCTION}

$\mathrm{B}$ ull fertility, defined as the ability to produce high quality, viable semen that when inseminated into a cow at the correct stage of the estrous cycle will result in conception and pregnancy, is a critical part of herd fertility efficiency, especially in herds using natural service (Kastelic, 2013).

Bull fertility is a complex trait which is determined by a wide range of factors including genetics (with large differ- ences within and between breeds), disease (both testicular and systemic), environment (such as heat stress), stress, and nutrition (Barth, 2018; Parkinson and McGowan, 2019; McGowan et al., 2018). Simply assuming that bulls are fertile will result in reduced fertility efficiency, as sub-fertile bulls are both common, with studies suggesting that after examination $\sim 25 \%$ of bulls will be unsuitable for use (Barth, 2018), and commonly used because they are not examined prior to use (Kastelic, 2013).

These findings led to the development of the breeding 
soundness evaluation (BSE) process, which identifies that bulls are physically sound, producing semen of good quality, and, if being used for natural service, have good libido and are capable of intromission (Barth, 2018). The BSE is a low-cost way of reducing, though not eliminating the risk of using sub-fertile bulls.

Nevertheless, despite the fact that sub-fertility is common and can have a significant impact in herds using natural service where one bull can be responsible for mating large numbers of cows, the use of the BSE is far less common than it should be (Barth, 2018). One of the reasons for this is the relatively complex nature of the BSE, especially the libido testing but also the collection and examination of the semen (Barth, 2018), while another is that traditionally, veterinary input has mainly focused on cow rather than bull fertility.

Scrotal circumference (SC) is routinely measured during the BSE and is an easy to measure estimate of testes size which has been reported to be strongly associated with spermatogenesis and fertility (Perry et al., 2008; Godfrey and Dodson, 2005). Several studies of BSE have recommended SC as a useful indicator for evaluation of yearling bulls (Parkinson, 2004; Silva et al., 2014). SC is closely related to puberty with $52 \%$ of bulls being pubertal when $\mathrm{SC}$ is $\geq 28 \mathrm{~cm}$ and $97 \%$ when $\mathrm{SC}$ is $\geq 30 \mathrm{~cm}$ (Parkinson, 2004). These findings are reflected in the recommendation (McGowan et al., 2002), that, in 2-year-old Bos indicus and indicus-derived bulls on native vegetation in arid areas, SC should be $\geq 28 \mathrm{~cm}$, with $<3 \%$ of bulls failing to meet this target. SC continues to increase after puberty so the target SC for 3+ year old bulls set by McGowan et al. (2002) was $34 \mathrm{~cm}$.

Another advantage of SC is that it is highly heritable (Quirino and Bergmann, 1998), so using bulls with large SCs will select for bulls with large SCs. SC has been related to fertility, for example McCosker et al. (1989) reported that, in Brahman bulls kept in Northern Australia, SC was correlated with the number of calves produced by a bull. Although not all studies have shown such an effect, differences between studies may be due to the population that was examined (Parkinson, 2004). Thus, at least in some populations of cattle, $\mathrm{SC}$ may be a simple, repeatable measure that can be easily implemented as a management tool for the selection of bulls with, on average, higher fertility, especially if it is used alongside a full clinical examination with an additional focus on the reproductive tract.

The fertility of Mpwapwa breed bulls has declined over a period of many years, reflected in an increasing inability to successfully breed cows effectively and efficiently (Kabuni, 2017). As part of a programme for improving Mpwapwa breed cattle, a limited BSE with a focus on structural soundness and movement is undertaken on all available bulls prior to every breeding season. The aim of this study was thus to identify whether in this herd there was an association between SC of Mpwapwa bulls and their subsequent conception rate.

\section{MATERIALS AND METHODS}

\section{STUdy AREA}

TALIRI Mpwapwa is located at $36^{\circ} 30^{\prime} \mathrm{E}, 26^{\circ} 20^{\prime} \mathrm{S}$ and is $1000 \mathrm{~m}$ above sea level. The area has two major seasons, dry and wet, running from May to November and December to April respectively. It has a daily mean temperature range of $24-29^{\circ} \mathrm{C}$ with an annual total rainfall of about $720 \mathrm{~mm}$. The soils of the institute's farm are sandy loams and clay loams with $\mathrm{pH}$ varying from $5.6-7.7$ and 5.3 to 8.6 for top and sub-soils respectively. Hyperrhenia rufa, Themeda spp, Cynodon dactylon and Chloris gayana are the species of grass grazed by livestock at the institute's farm. This study was conducted at the end of the dry season.

\section{Selection of BUlls AND Cows}

A written approval for all animal related assessment was obtained from Tanzania Livestock Research Institute (TALIRI) prior to the start of the study.

In August 2020, 46 Mpwapwa bulls aged $\geq 3$ years, with no records of reproductive problems, were examined prior to use in the Sept - Nov 2020 breeding season in order to obtain eight bulls to be used for mating in that season. A reduced BSE was conducted with the evaluation being limited to: SC (measured using a standard cloth tape measure placed around the scrotum at its widest point), and structural soundness and movement (examination of the legs, joints, muscles, eyes, testes, prepuce, and penis).

No examination of semen or of libido was undertaken. Of the bulls, which passed the test of structural soundness and movement (23), the eight bulls with the largest SC were selected to be used for the subsequent breeding season. Their weights and body condition scores were recorded.

In August 2020, 424 Mpwapwa cows were manually diagnosed for pregnancy using the per rectal palpation method. Non-pregnant cows were eligible for breeding in the Sept - Nov 2020 breeding season provided they weighed $>180$ $\mathrm{kg}$ and their body condition score was 3 to 4 on a BCS scale of 1 to 5 (Nicholson and Sayers, 1987). Three-hundred and twenty-four cows met these conditions.

\section{Management and treatment of animals}

The selected cows (324) and bulls (8) had access to unrestricted grazing in selected paddocks, which is the normal grazing plan for the TALIRI Mpwapwa farm. There was 
Table 1: Mating plan for the Mpwapwa cattle during Sept - Nov 2020 breeding season at TALIRI Mpwapwa farm.

\begin{tabular}{llll} 
Groups & Number of cows & Bull ID & Pregnancy diagnosis date \\
\hline Group 1 & 62 & 1837 & \\
\hline Group 2 & 46 & 14739 & $1^{\text {st }}-14^{\text {th }}$ Dec, 2020 \\
\hline Group 3 & 42 & 16941 & \\
Group 4 & 38 & 3902 & \\
Group 5 & 37 & 15195 & \\
Group 6 & 36 & 16133 \\
\hline Group 7 & 36 & 14722 & \\
Group 8 & 27 & 16643 &
\end{tabular}

Table 2: Descriptive data of eight Mpwapwa bulls from records and examinations, and results of final pregnancy examination in each breeding group of Mpwapwa cattle.

\begin{tabular}{|llllllll} 
Bull ID & $\begin{array}{l}\text { Bull age } \\
\text { (years) }\end{array}$ & $\begin{array}{l}\text { Scrotal } \\
\text { circumference } \\
\text { (cm) }\end{array}$ & $\begin{array}{l}\text { Breeding } \\
\text { group }\end{array}$ & $\begin{array}{l}\text { Total number of } \\
\text { cows in breeding } \\
\text { group bred }\end{array}$ & $\begin{array}{l}\text { Number of } \\
\text { cows } \\
\text { conceived }\end{array}$ & $\begin{array}{l}\text { Number of cows } \\
\text { failed to conceived }\end{array}$ & $\begin{array}{l}\text { Final } \\
\text { pregnancy rate } \\
\text { (\%) }\end{array}$ \\
\hline 1837 & 5 & 30 & 1 & 62 & 32 & 30 & 52 \\
\hline 14739 & 3 & 27 & 2 & 46 & 39 & 7 & 85 \\
\hline 16941 & 5 & 29 & 3 & 42 & 32 & 10 & 76 \\
\hline 3902 & 9 & 30 & 4 & 38 & 21 & 17 & 55 \\
\hline 15195 & 5 & 32 & 5 & 37 & 32 & 5 & 87 \\
\hline 16133 & 7 & 32 & 6 & 36 & 22 & 14 & 61 \\
\hline 14722 & 3 & 30 & 7 & 36 & 20 & 16 & 56 \\
\hline 16643 & 6 & 31 & 8 & 27 & 20 & 7 & 74 \\
\hline
\end{tabular}

no supplementation of either concentrates or minerals. All cattle were treated with anthelminthic (Levamizole hydrochloride $-10 \% \mathrm{Inj}, 1 \mathrm{ml}$ per $20 \mathrm{~kg}$ of bodyweight, Eagle Vet. Tech Co. Ltd, Kenya) three months prior to the start of the breeding season, this is as according to the deworming regimen of TALIRI Mpwapwa farm. Dipping was conducted once every week using Paranex (100g of Alphacypermethrin per liter, Farm base Ltd, Tanzania) to control ecto-parasites. All selected cattle were weighed and their body condition scored prior to and at the end of the breeding season.

\section{STUDY DESIGN}

The 324 cows were separated into eight groups, with size based on the availability of herdsmen (Table 1). Each group was assigned one bull. Cows were put with the bulls on $1^{\text {st }}$ September 2020 and bulls were removed on $30^{\text {th }}$ November 2020. Pregnancy diagnosis was conducted for all eight groups starting from $1^{\text {st }}-14^{\text {th }}$ of December 2020 using an ultrasound scanner (Minitube International Co, Germany) with a $6 \mathrm{mHz}$ linear probe.

\section{DATA ANALYSIS}

All the analysis were performed using IBM SPSS Statistics Version 26. The data were analyzed using a series of logistic regression models with pregnancy status as the outcome variable. Variables for inclusion in the final multivariable model were selected using univariable models, with the variable being included in the final model if $\mathrm{P}$-value of the univariable model was $<0.25$. All variables collected in relation to the bulls prior to breeding (see Table 2) were used, as well as group size. All variables were included as continuous variables except for BCS, which was used as a categorical predictor. Prior to use in the final model, in order to prevent multi-collinearity, the selected variables were tested for correlation using Spearman's rank test. Correlations $\geq 0.8$ precluded both variables being used in the test, in such cases the variable chosen to remain was the one with the highest odds ratio in their univariable model.

\section{RESULTS}

Overall of the 324 cows bred, 218 became pregnant from $1^{\text {st }}-14^{\text {th }}$ of December 2020. Table 2 summarizes for each breeding group the bull data and the final pregnancy rate. The age of bulls was ranging from 3 to 9 years, with scrotal circumference of 27 to $32 \mathrm{~cm}$. Different groups of cows exhibited different pregnancy rates ranging from 52 to $87 \%$ (Table 2).

Of the five variables used in the univariable models only pre-breeding weight had a $\mathrm{p}$-value of $>0.25$, so the four remaining variables (age, pre-breeding $\mathrm{BCS}, \mathrm{SC}$ and total number of cows bred) were tested for correlation. All 
$\rho$ were $<0.65$, so all four variables were included in the multivariable logistic regression model. The results of the multivariable model are summarized in Table 3.

Table 3: Effect of bull variables (pre-breeding body condition score (BCS), age and scrotal circumference (SC)) and breeding group size on odds of pregnancy during breeding season for Mpwapwa cows.

\begin{tabular}{|lll|}
\hline Variable & Odds ratio $(\mathbf{9 5 \% C I})$ & P-value \\
\hline Pre-breeding BCS & $0.29(0.15$ to 0.57$)$ & $<0.001$ \\
\hline Age (years) & $0.97(0.84$ to 1.13$)$ & 0.71 \\
\hline SC $(\mathrm{cm})$ & $1.05(0.84$ to 1.3$)$ & 0.69 \\
$\begin{array}{l}\text { Total number of cows in } \\
\text { breeding group }\end{array}$ & $0.98(0.96$ to 1.01$)$ & 0.18 \\
\hline
\end{tabular}

Of all the variables analyzed, in the multivariable regression, only pre-breeding BCS of the bull was found to have a statistically significant association with odds of pregnancy $(\mathrm{p}<0.001)$. After having accounted for age, SC and number of cows in the breeding group, cows in a breeding group that had a bull with a pre-breeding BCS of 3.0 had only 0.29 times ( $95 \%$ CI 0.15 to 0.57 ) the odds of getting pregnant compared to cows in a breeding group with a bull with BCS of 3.5. That is if the pregnancy rate at the end of the breeding season was $70 \%$ in a breeding group with a bull whose pre-breeding BCS was 3.5, the expected pregnancy rate for a group with a bull of BCS 3.0 would be only $40 \%$ (95\% CI 26 to $57 \%)$.

In contrast, for $\mathrm{SC}$, the data were consistent with no association between $\mathrm{SC}$ of a bull and the odds of pregnancy. The analysis found that in this data set (having accounted for age, SC and number of cows in the breeding group) for every $1 \mathrm{~cm}$ increase in SC, the odds of pregnancy increased by 1.05 times. The $95 \%$ CI for this odds ratio show that the data were compatible with a decrease in pregnancy rate as SC increased (lower 95\%CI 0.84) and a moderate increase (upper 95\% CI 1.3). That is if the pregnancy rate for a group with a bull with a $\mathrm{SC}$ of $27 \mathrm{~cm}$ (the smallest recorded in this study) was 60\%, the expected pregnancy rate for a group with a bull with a $\mathrm{SC}$ of $32 \mathrm{~cm}$ (the largest recorded in this study) would be $61 \%$. However, the $95 \%$ confidence intervals of this estimate would be quite wide (38 to $85 \%)$.

\section{DISCUSSION}

The aim of this study was to assess the effect of scrotal circumference on pregnancy rates in Mpwapwa breed cattle during the Sept - Nov 2020 breeding season of the TALIRI Mpwapwa farm. As well as data on scrotal circumference, data on potential confounders, bull age and pre-breeding BCS were also included in the analysis, as well as because of staff availability issues during the breeding season and group size (see Table 1). Of these five factors, only BCS was found to have significant association with the odds of pregnancy. The estimated effect of BCS was quite large, with cows in a breeding group with a bull with a BCS having $<1 / 3$ the odds of getting pregnant. This effect may be mediated, at least in part, by an effect on bull libido. Torres-Aburto et al. (2020) analyzed data from 223 bulls undertaken in Brazil of a mix of Zebu, European and crossbred bulls and reported that bulls with a BCS of 4 had a mean libido score of $>8$, while bulls with a BCS of 3 had a mean libido score of 7 . For these libido scores, the mean pregnancy rates reported by Torres-Aburto et al. (2020) for bulls were 43 and 37 respectively, consistent with BCS reducing pregnancy rates by reducing libido. However, the impact on pregnancy rate of reduced BCS reported by Torres-Aburto et al. (2020) was much less than that reported in this study. It may be that the impact on libido of poor BCS is greater in Mpwapwa bulls than in the bull breeds examined by Torres-Aburto et al. (2020) or that the impact of poor BCS on pregnancy rate in this study was mediated by factors other than libido. Further research is required especially on the association between BCS and libido in Mpwapwa bulls.

In contrast this study which did not demonstrate a similar association between SC and pregnancy rate. The estimated odds ratio (1.05) indicated only a small positive effect in the study animals, however the confidence intervals of this estimate are wide and compatible with both large decreases and large increases in pregnancy rate as $\mathrm{SC}$ gets larger. Previous studies (e.g. Parkinson, 2004; Perry et al., 2008; Silva et al., 2014) have suggested that there is a generally positive association between SC and subsequent pregnancy rate, but those studies involved more bulls and thus had a greater power to detect an effect of SC than the current study. For example, Torres-Aburto et al. (2020) utilized data from 223 bulls and found a significant but moderate association between $\mathrm{SC}$ and pregnancy rate $(r=0.21)$, an association that would have been small to be detected in this study. Further research on SC in Mpwapwa cattle is required both in terms of its association with fertility parameters such as pregnancy rate, including whether there is an interaction between BCS and SC. But also at the individual bull level including whether measuring $\mathrm{SC}$ earlier would be more effective in predicting bull fertility (Menegassi et al., 2019) and how, in Mpwapwa bulls, SC relates to semen production (Susilawati et al., 2020).

\section{CONCLUSION}

The results of this study suggest that improving pre-breeding bull BCS and choosing bulls based on BCS could be a good strategy for improving pregnancy rates in cows bred 
with Mpwapwa bulls. The results also suggest that this may be a better strategy than choosing bulls based on SC. However, this was a small-scale study with only eight bulls, with a limited range of $\mathrm{BCS}$, so further research is required to confirm these suggestions. In regard to SC, no conclusions was made to use $\mathrm{SC}$ as a predictor of pregnancy rate because of the limited data in this study. So further research on the association between SC and pregnancy rate in Mpwapwa bulls is needed, including identifying whether there is an interaction between BCS and SC and their effect on subsequent fertility.

\section{ACKNOWLEDGEMENTS}

We express our sincere gratitude to all staff members at TALIRI Mpwapwa especially those in the department of cattle research (Erick Mbisha, Deogratias Masao, Malongo Mwalingo, Mary Millinga, Sylvanus Sindamakoko, Jackson Nyami, Geofrey Matimya and Salome Nyabusani) as well as Baraka Mwamnyanyi (a freelancer veterinarian) for their support and collaboration during the time of conducting the study. More importantly, we also thank the administration of TALIRI Mpwapwa for the permission to conduct this study in its environment. The completion of this study was facilitated by the support of the Tanzania Livestock Research Institute (TALIRI) through provision of research infrastructure, animals and staff, Massey University (MU) from New Zealand as well as the Tanzania Commission of Science and Technology (COSTECH) through provision of publication assistance.

\section{CONFLICT OF INTEREST}

Authors do not have any conflict of interest.

\section{AUTHORS CONTRIBUTION}

Designing, coordination, supervision and implementation of the study. Also data collection, analysis, interpretation and discussion of the results. Finally, development of the manuscript.

\section{REFERENCES}

- Barth AD (2018). Review: The use of bull breeding soundness evaluation to identify sub fertile and infertile bulls. Animal. 12(51): 158 - 164. https://doi.org/10.1017/ S1751731118000538

- Godfrey RW, Dodson RE (2005). Breeding soundness evaluations of Senepol bulls in the US Virgin Islands. Theriogenology., 63(3): 831-840. https://doi.org/10.1016/j. theriogenology.2004.05.001

- Kabuni KT (2017). Comparative study between fixed time artificial insemination and natural mating on reproductive performance (conception and pregnancy rates) of Mpwapwa breed cows in Tanzania. MSc. Thesis, Institute of Veterinary, Animal and Biomedical Sciences (IVABS), Massey University, Palmerston North, New Zealand. http://hdl. handle.net/10179/12199, 2017.

-Kastelic JP (2013). Male involvement in fertility and factors affecting semen quality in bulls. Anim. Front. 3(4): 20-25. https://doi.org/10.2527/af.2013-0029

-Kastelic JP, Thundathil JC (2008). Breeding Soundness Evaluation and Semen Analysis for Predicting Bull Fertility. Reprod. Domest. Anim. 43(s2): 368-373. https://doi. org/10.1111/j.1439-0531.2008.01186.x

- McCosker TH, Turner AF, McCool CJ, Post TB, Bell K (1989). Brahman bull fertility in a north Australian rangeland herd. Theriogenology.,32: 285 - 300.https://doi.org/10.1016/0093691X(89)90319-1

-McGowan M, Holland MK, Boe-Hansen G (2018). Review: Ontology and endocrinology of the reproductive system of bulls from fetus to maturity. Animal, 12, supplement. 1: 19 26. https://doi.org/10.1017/S1751731118000460

-McGowan MR, Bertram JD, Fordyce G, Fitzpatrick LA, Miller RG, Jayawardhana GA, Holroyd RG (2002). Bull selection and use in northern Australia. Anim. Reprod. Sci. 71(1): 2537. https://doi.org/10.1016/S0378-4320(02)00023-4

- Menegassi SRO, Pereira GR, McManus C, Roso VM, Bremm C, Koetz Jr C, Lopes JF, Barcellos JOJ (2019). Evaluation and prediction of scrotal circumference in beef bulls. Theriogenology. 140: 25 - 32. https://doi.org/10.1016/j. theriogenology.2019.08.008

- Nicholson MJ, Sayers AR (1987). Repeatability, reproductibility and sequential use of condition scoring of Bos indicus cattle. Trop. Anim. Hlth Prod., 19: 127 - 135. https://doi. org/10.1007/BF02239705

- Nicholson MJ, Sayers AR (1987). Relationship between body weight, condition score and heart girth changes in Boran cattle. Trop. Anim. Hlth Prod., 19: 115 - 120. https://doi. org/10.1007/BF02297329

- Parkinson TJ (2004). Evaluation of fertility and infertility in natural service bulls. Vet. J. 168(3): 215-229. https://doi. org/10.1016/j.tvj1.2003.10.017

- Perry GW, Julie, Daly R (2008). Reproductive fertility in herd bulls. Anim. Range Sci.

-Quirino CR, Bergmann JA (1998). Heritability of scrotal circumference adjusted and unadjusted for body weight in Nellore bulls, using univariate and bivariate animal models. Theriogenology., 49 (7): 1389 - 1396. https://doi. org/10.1016/S0093-691X(98)00085-5

- Silva MR, Pedrosa VB, Borges-Silva JC, Guimaraes JD, Albuquerque LG (2014). Genetic parameters for scrotal circumference, breeding soundness examination and sperm defects in young Nellore bulls. J. Anim. Sci., 91: 4611 - 4616 https://doi.org/10.2527/jas.2012-6067.

-Susilawati T, Sholikah N, Wahjuningsih S, Herwiyanti E, Kuswati, Yekti APA (2020). Relationship of scrotal circumference with spermatozoa production in various breed of Indonesian local bulls. American J. Anim. Vet. Sci. 15(2): 102 - 107. https://doi.org/10.3844/ajavsp.2020.102.107

-Torres-Aburto VF, Barrientos-Morales M, Hernández-Flores $\mathrm{H}$, Rodríguez-Andrade A, Cervantes-Acosta P, Landi V, Beltran AH, Domínguez-Mancera B (2020). Breeding soundness examination and herd proficiency of local genetic groups of bulls in tropical environment conditions in Veracruz, Mexico. Italian J. Anim. Sci. 19: 1, 840 - 855. https://doi.org/10.1080/1828051X.2020.1803773 